\title{
Opportunities and Challenges in the Value Chain for Companies through a Changing Understanding of Products on the Example of Shape Memory Actuators Systems
}

\author{
Rathmann Christian*, Klenk Stefanie and Kreimeier Dieter
}

Department of Mechanical Engineering, Institute of Product and Service Engineering Chair of Production Systems, Ruhr-University Bochum, Germany

\begin{abstract}
The business environment is changing. In the past, just selling products proved to be sufficient. Internationalization, decreasing revenues and technological competition are forcing companies to rethink their products and thus their business models. Today's technological products offer new functionalities and therefore potential for services. However, more and more electronics and information technology is required. Consequently, the understanding of value creation is changing and accordingly traditional value chains have to be extended to meet these demands. Nevertheless, the extended value chain can help companies in developing proper business models; allow for a differentiation from competitive companies and for the identification of required competences. Shape memory actuator systems are good examples to illustrate these issues. This paper starts by shortly defining products, services and industrial productservice systems. Additionally, an overview about existing services in mechanical engineering is given and compared to services in general. The attention is then drawn to shape memory actuators in that their possible and existing services over their lifetime are discussed. Based on this, an integrated value chain for shape memory actuator systems is created which considers traditional value-added steps for products as well as new steps due to changing technology and the increasing importance of service. In relation to this, existing business models for shape memory actuator systems are analyzed and hypotheses for future business models are developed. For these hypotheses, opportunities and challenges as well as necessary competencies within this integrated value chain are highlighted. In this context, especially features of small and medium-sized companies are taken into account. Further studies should be performed to investigate shape memory applications regarding its value chain and its potentials for services. Moreover, value chains in combination with services as well as technology in general should be analyzed. Especially small and mediumsized companies are excellent examples to illustrate the developed business models.
\end{abstract}

Keywords: Business model; Service; Shape memory actuator; Small and medium-sized enterprises; Value chain

\section{Introduction}

Today's market environment is changing rapidly. Increasing price erosion due to internationalization, decreasing profits and the increasing number of products that are technologically equivalent are forcing companies to rethink their business models [1]. Companies that only sell products are increasingly reaching their limits. Customers are demanding more and more holistic system solutions, wherefore services are becoming more and more important. Schonherr [2] has stressed that high customer value as well as provider value can be created by combining products and services. Hereby companies are becoming an important and unique selling point, are increasing customer loyalty and, in consequence, their competitiveness. The ongoing networking of information via "industry 4.0", among others, and the increasing importance of electronics in engineering are changing the understanding of value adding. A value chain or value chain system which takes products as well as services into account and is well integrated into industry can help companies in a strategic positioning within the industry. This integrated value chain makes it possible to illustrate the required competences and compare the core competences of companies. This is especially essential for small and medium-sized enterprises (SME) due to their limited resources. A shape-memory alloy (SMA, smart metal, memory metal, memory alloy, muscle wire, smart alloy) is an alloy that "remembers" its original shape and that when deformed returns to its pre-deformed shape when heated. This material is a lightweight, solid-state alternative to conventional actuators such as hydraulic, pneumatic, and motor-based systems. Shape-memory alloys have applications in industries including automotive, aerospace, biomedical and robotics. The integrated value chain and opportunities and challenges for SMEs are illustrated on the example of shape memory alloy (SMA) actuator systems. SMA actuator systems enable system solutions which consider products as well as services in the field of actuating elements, and require a new understanding of value creation. By incorporation of surface-modified superparamagnetic nanoparticles into shape memory polymer matrices, remote actuation of complex shape transitions by electromagnetic fields is possible.

\section{Definition of Products, Services and Industrial Product- Service Systems}

Products are defined as objects which are materialized and synthesized. These objects can be divided into raw materials, production goods, equipment as well as consumer goods [3]. In literature, various ways to define services are given. A common possibility to depict services is to define constitutive characteristics [4]. According to Laurischkat [5], the following constitutive characteristics can be named:

*Corresponding author: Rathmann Christian, Department of Mechanical Engineering, Institute of Product and Service Engineering Chair of Production Systems, Ruhr-University Bochum, Germany, Tel: +49 (0)234 32-28930; Fax: +49 (0)234 32-08930; E-mail: rathmann@Ips.rub.de

Recieved January 23, 2015; Accepted February 28, 2015; Published March 10 , 2015

Citation: Christian R, Stefanie K, Dieter K (2015) Opportunities and Challenges in the Value Chain for Companies through a Changing Understanding of Products on the Example of Shape Memory Actuators Systems. J Entrepren Organiz Manag 4: 130. doi:10.4172/2169-026X.1000130

Copyright: (c 2015 Christian R, et al. This is an open-access article distributed under the terms of the Creative Commons Attribution License, which permits unrestricted use, distribution, and reproduction in any medium, provided the original author and source are credited. 
- Immaterialism,

- Inability of storage,

- Integration of an external factor,

- The individuality of contracts and

- The uno-actu-principle [6]

Immaterialism means the intangibility of the output. Even though the result of the service is intangible, its implication might still be inseparable from a good [7]. This characteristic comes along with its inability to be stored. Another constitutive characteristic is the (Figure 1), characteristics of products and services integration of an external factor. That implies that the customer takes the decisions and is the investor of the service. Consequently, the external factor is the recipient of the service. As the services are customized and adjusted to the integration of the external factor, the individuality of contracts is necessary [8]. The uno-actu-principle signifies the simultaneous preparation of a service and its consumption by the customer [9]. Figure 1 summarizes the characteristics of products and services. Industrial product-service systems (IPSS) are distinguished by their integrated and mutually dependent process of planning, developing as well as delivering goods and services. This applies to the entire IPSS life-cycle.

\section{Existing Services in the Field of Mechanical Engineering in Comparison to Overall Services}

In order to disaggregate the term "services", further clarification is given. Four categories support this procedure:

- Constitutive differentiation

- Institutional differentiation

- Negative differentiation

- $\quad$ Enumerative differentiation [10].

The first category, the constitutive differentiation, was depicted in chapter 2 and is most suitable to define services in comparison to products in science [11]. The institutional differentiation assumes that services are only performed within the tertiary sector. This sector implies trade, banks, insurance, traffic etc. [10]. However, this approach is insufficient as services are also performed within the primary (agriculture) and the secondary (manufacturing) sector [9]. The next category, the negative differentiation, differs between material and immaterial characteristics. Therefore, services comprise everything that cannot be assigned to a product [11]. Last, the enumerative differentiation tries to identify the characteristics of services by listing

\begin{tabular}{|c|c|}
\hline Products: & Services: \\
\hline $\begin{array}{l}\text { - Material } \\
\text { - Synthesized }\end{array}$ & $\begin{array}{l}\text { - Immaterial } \\
\text { - Unable to be stored, } \\
\text { - Integrated of an external factor, } \\
\text { - Comprised by the individuality of contracts and } \\
\text { - The uno-actu-principle }\end{array}$ \\
\hline Examples for products: & Examples for services: \\
\hline $\begin{array}{l}\text { Manufactured product, manufactured end } \\
\text { product, material }\end{array}$ & $\begin{array}{l}\text { Process, potential and result, marketing, } \\
\text { consulting project }\end{array}$ \\
\hline
\end{tabular}

Figure 1: Characteristics of products and services..

$\begin{array}{cccccc}\text { Plant safety } & \text { Training } & \begin{array}{c}\text { Quality } \\ \text { assurance }\end{array} & \text { Ramp-up } & \begin{array}{c}\text { Technology } \\ \text { placement }\end{array} & \text { Simulation } \\ \begin{array}{c}\text { Functional } \\ \text { assurance }\end{array} & \text { Availability } & \begin{array}{c}\text { Process } \\ \text { optimization }\end{array} & \begin{array}{c}\text { Full-service- } \\ \text { leasing }\end{array} & \text { Financing } & \begin{array}{r}\text { Development of } \\ \text { marketchannels }\end{array} \\ \begin{array}{c}\text { Management } \\ \text { consulting }\end{array} & \begin{array}{c}\text { Technical } \\ \text { consulting }\end{array} & \text { Marketing } & \text { Maintenance } & \begin{array}{c}\text { Component } \\ \text { construction }\end{array} & \text { Transportation } \\ \text { IT solutions } & \begin{array}{c}\text { Service } \\ \text { centers }\end{array} & \text { Certification } & \text { Modernization } & \begin{array}{c}\text { Increase in } \\ \text { productivity }\end{array} & \begin{array}{l}\text { Innovation } \\ \text { safety }\end{array}\end{array}$

Figure 2: Services with Services in the Field of Mechanical Engineering [1].

examples [12]. This approach is applied to define services in the field of mechanical engineering. Therefore, a table enumerates several examples of services in comparison to services in the field of mechanical engineering in the following figure. The underlined examples apply to both, services in the field of engineering as well as general services. In practice, the enumerative differentiation is appropriate and sufficient in order to generate a rough classification [13] (Figure 2).

\section{Products and Services in the Field of Shape Memory Actuators}

Due to the change in customer requirements and the opportunity to increase company return, services are increasingly needed. SMA actuators and their unique features have great potential regarding service applications. In Figure 3 product and service potentials of SMA actuator systems are illustrated, which are distinguished into the categories of before usage and after usage. SMA-relevant aspects are described in the following. The first category before usage focuses on product customization. It is possible to modify products for various applications. Although these are customized to some extent, they are still highly standardized. Thanks to the thermal sensitivity, SMA actuators can be individualized to customer-specific needs, without changing the geometry. A good example in this context is the FGABasic SMA actuator, which was already discussed in [14]. According to Czechowicz et al. [15] it is possible to use SMA actuators to protect the intellectual property of products due to its unique resistance behavior. To identify counterfeit products on the resistance curve, knowledge about heat treatment and the alloy composition of SMAs are crucial [16]. Consulting and software support for SMA actuators is of utmost importance. Every product has to be tested due to the lack of norms and guidelines. Also, the certification of product or quality properties of SMA actuators is possible. Additionally, knowledge and the level of awareness are very limited in companies and thus external support during the product development is promising. This can range from the design to the contract development of SMA actuator systems. The second category covers the usage of services or product features of SMA actuators like changing operating conditions, condition monitoring and the compensation of fatigue as well as maintenance. By heat treatment and constructive solutions, SMA actuators are capable of adapting to changing operating conditions, for example, a change in environmental factors. Czechowicz et al. [15] demonstrated a concept of an SMA valve with a switching system which uses a locking function to operate on two different environmental temperatures. The use of a resistance-controlled SMA actuator system can partly compensate the reduction in elongation and response time. Moreover, overheating can be prevented through this control system [17]. A unique feature of SMAs is their integrated sensor function, which can be used to control actuator motion and getting information about actuator fatigue. By measuring the resistance, conclusions about the material condition and 
Citation: Christian R, Stefanie K, Dieter K (2015) Opportunities and Challenges in the Value Chain for Companies through a Changing Understanding of Products on the Example of Shape Memory Actuators Systems. J Entrepren Organiz Manag 4: 130. doi:10.4172/2169-026X.1000130

Page 3 of 6

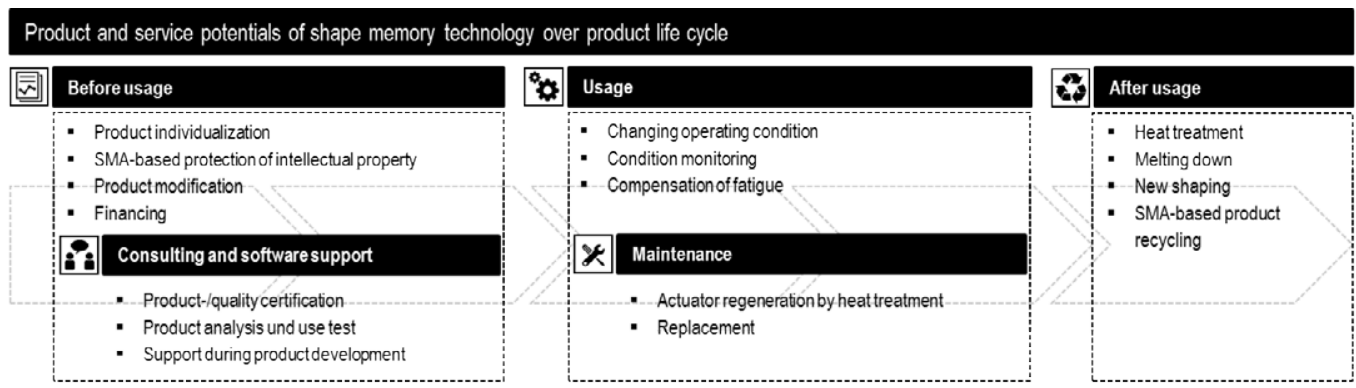

Figure 3: Product and service potentials of shape memory technology over product life cycle.

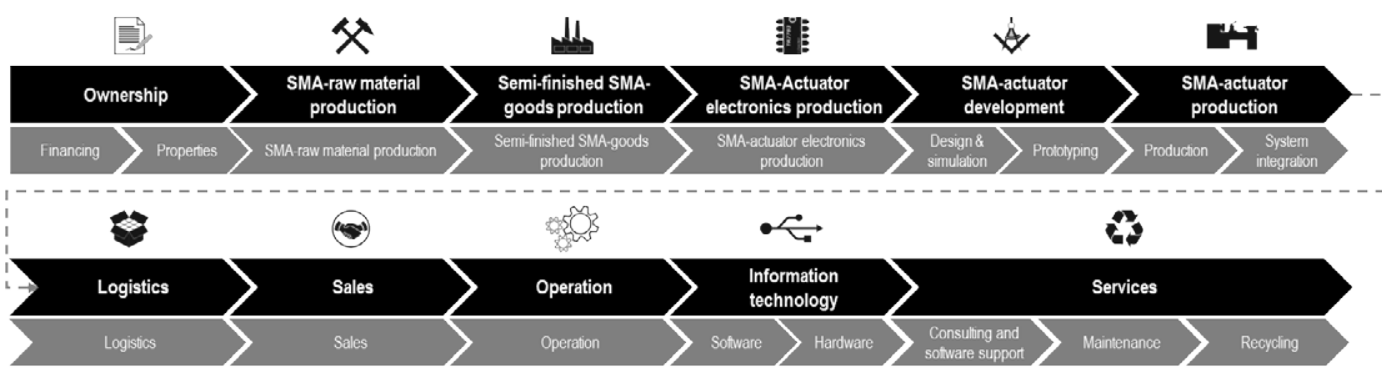

Figure 4: Integrated value chain for shape memory actuator systems.

material history can be drawn. Thus, countermeasures can be taken, if the resistance decreases below a certain value and possible breakdowns of the system prevented [18]. Meier et al. [19] proved the integrated sensor function. With respect to maintenance, SMA actuators have innovative properties. Unlike most materials, SMA actuators can recover to their original mechanical properties and previous shape by heat treatment. For this, the SMAs have to be exposed to a certain temperature for a defined time, which can be also done through a controlled current flow or annealing process [20-22]. Besides SMA actuator regeneration by heat treatment, SMA actuators can be replaced. After the usage of SMA actuators, a distinction can be made between the recycling of SMA actuators and a recycling based on SMA actuators. The use of SMA-based fasteners to recycle complex products can reduce assembly time and especially disassembly time, which leads to lower total recycling costs [23]. More details about recycling and regeneration by heat treatment as well as recycling strategies can be found in [22]. Furthermore, the resource efficiency can be increased by reusing SMA actuators for different applications. Changing the shape of SMA actuators, for example, the size or the length or using heat treatment to reconfigure the activation behavior can reduce required resources for production. Moreover, by melting down SMA actuators, the material can be reused for production.

\section{Integrated Value Chain for Shape Memory Actuator Systems}

According to the classical understanding for value creation within the mechanical engineering of SMA products, the first step is the production of raw material. Depending on the product complexity, the raw material production is usually followed by the production of semifinished products like wires or plates. Finally, the product is produced by integrating or assembling all components required. Thus, the physical value creation is completed. After the product is distributed and sold, value creation is completely finished. Due to the increasing importance of electronics in mechanical engineering, the production of components for the control of SMA actuators has to be considered. The characteristics of SMAs are highly beneficial to create new products which can also add value from the customer perspective. The integrated sensor function of SMAs enables the condition monitoring of SMA actuator systems. It is possible to monitor the functionality of SMA actuator systems, i.e. the so-called need-based maintenance. Such solutions require an additional value adding stage - the information technology (IT). IT provides the infrastructure, hardware and software for information exchange and processing. This can imply the data exchange and software-based interpretation of collected data to the probability of failure or maintenance as well as the compensation of fatigue. Furthermore, the disassembly of SMA-based fasteners can be thermally initiated and thus the semi-automation of recycling or disassembly processes is possible. Therefore, these fasteners can shorten the disassembly time and thus reduce costs. The capabilities in recycling SMAs allow for a price differentiation according to specific requirements. One example is the melting-down of SMA offcuts and exchanged SMA actuators to produce SMA raw material with various degrees of contamination. Regardless of SMA-technology-specific features, companies today have to consider how to determine the ownership structure in terms of customer needs. In this context, it is essential to clarify the financing of products. For an availability-oriented product solution, for example, the customer may not necessarily own the product [24]. In consequence, it is necessary to extend the value chain, particularly in the area of services. To capture the whole value adding of SMA products, the value chain in the field of mechanical engineering is not sufficient. A cross-industry view for the value chain is needed. Figure 4 illustrates the whole integrated value chain or value chain system for shape memory products. The value chain steps well illustrate the linkage and diversity in the production and use of SMA. 
Citation: Christian R, Stefanie K, Dieter K (2015) Opportunities and Challenges in the Value Chain for Companies through a Changing Understanding of Products on the Example of Shape Memory Actuators Systems. J Entrepren Organiz Manag 4: 130. doi:10.4172/2169-026X.1000130

Page 4 of 6

\section{Existing Business Models for Shape Memory Actuators}

The classification of value adding steps of today's business models is based on publicly available information sources such as the SMA network [25], news articles, company websites or literature. Nowadays, the applications in the field of SMA technology are dominated by the medical sector. Today, industrial applications play only a minor role despite their high potential for applications especially in areas like heating and ventilation engineering, mechanical and plant engineering as well as aerospace, due to its high, specific capacity and low weight. Value adding steps that are covered by today's business models are marked by dark gray bars. Future business model hypotheses are marked in light gray. Figure 5 illustrates only industrial applications and the respective value added steps.

When looking at the currently added value of business models, one focuses more on traditional value adding steps like production and less on services. The production of SMA raw material and semi-structured goods is dominated by medical companies. Thus, the value chain of today's business models is currently very limited and is marked by the production of SMA raw material characterized by small and mediumsized specialists. The newer value adding steps like services are interesting for companies with expertise in their value adding steps but without particular knowledge of SMA actuator systems. Hence, these value adding steps are interesting for future business models in the field of SMA actuator systems. Rathmann et al. [18] illustrated a serviceoriented business model based on an SMA actuator system.

\section{Hypotheses for Future Business Models Respecting Challenges and Opportunities for Small and Medium- Sized Enterprises}

Analyzing existing business models has revealed that these are less integrated. Certain business models like the SMA-electronic provider or engineering service provider cover particular value adding steps. However, they are not oriented to the integrated value chain for shape memory actuator systems. It can be stated that the potential for innovative product solutions based on SMAs is hardly used and necessary competence for these are not covered by any company in the field of SMA actuator systems. These potentials for companies are illustrated by the business model hypotheses, which are described below. The recovery of the SMA material through recycling is interesting for SMA-(raw) material producers. They have the necessary equipment and process know-how. An important prerequisite for this hypothesis is the establishment of SMA actuators in industrial mass production to gain the critical demand for SMA material, semi-finished SMA goods and SMA actuators. Fully-integrated SMA providers are responsible for the SMA system integration as well as the production of semi-finished SMA goods and SMA components. Their access to alloy production allows them to develop more complex alloy systems as are required by the industry. SMA actuator producers, which are specialists in designing and producing SMA actuators, can extend their core business by designing and producing the SMA-actuator electronic as well. Hereby, they will become integrated SMA-actuator producers. Furthermore, the vertical integration would also allow serving the value adding step service and information technology. SMA-engineering service providers protect their intellectual property through patents and thus secure their business models effectively against the competition. Their high engineering expertise enables them to develop software solutions for the maintenance concepts within the value adding step service and besides intense their activities in consulting and software support of SMA actuators. For SMA-electronic providers it is attractive to serve downstream as well as the value adding steps such as the design and prototyping of SMA actuators in combination with information technology and services. Their high knowledge in

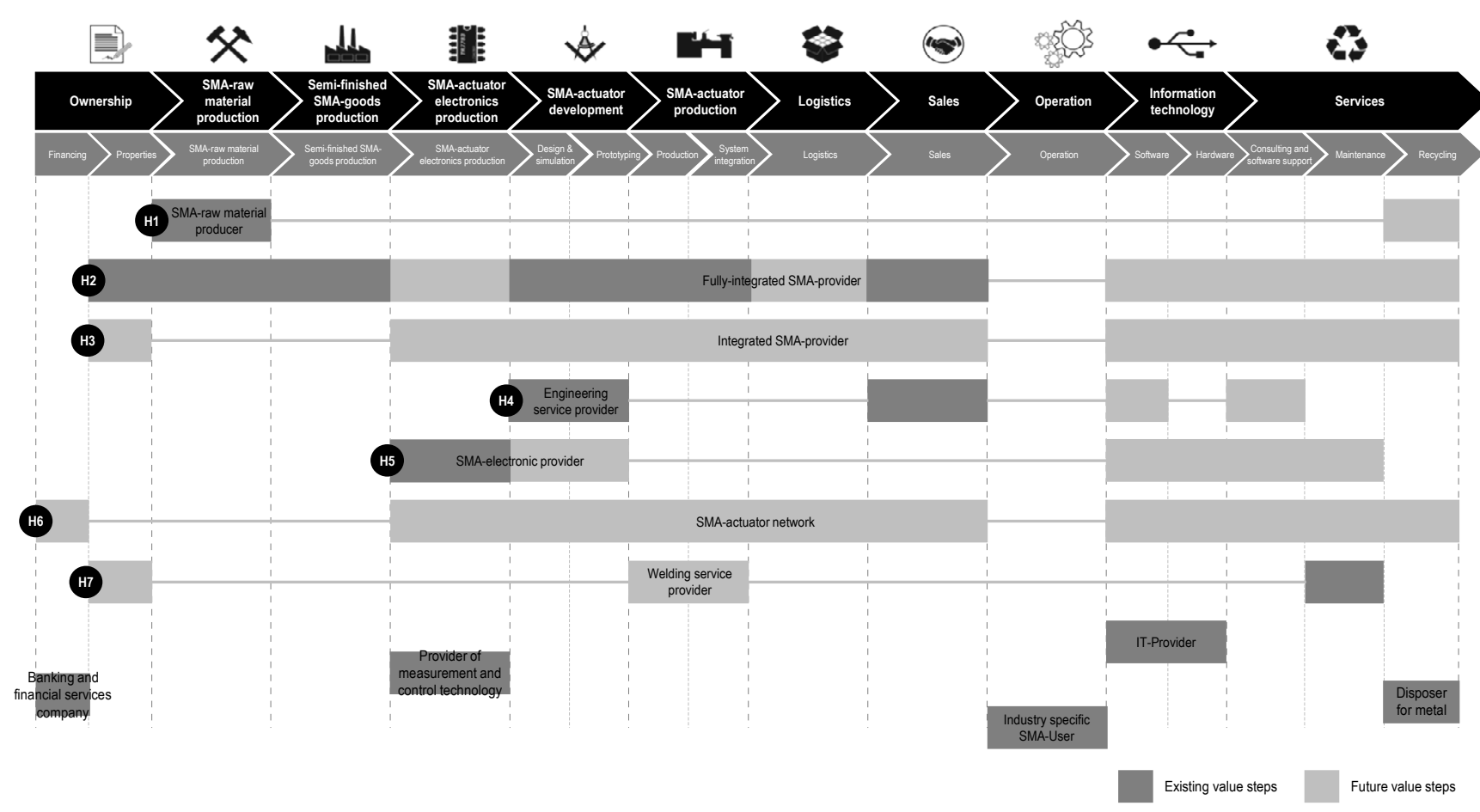

Figure 5: Existing and future business models for companies providing shape memory actuator systems within the integrated value chain. 
Citation: Christian R, Stefanie K, Dieter K (2015) Opportunities and Challenges in the Value Chain for Companies through a Changing Understanding of Products on the Example of Shape Memory Actuators Systems. J Entrepren Organiz Manag 4: 130. doi:10.4172/2169-026X.1000130

Page 5 of 6

electronics is becoming more and more important for SMA-actuator applications due to fatigue and activation behavior. SMA-actuator networks take advantage of core competencies of various providers. This business model hypothesis is similar to the fully integrated SMA provider model but instead of one large-sized company, small and medium-sized enterprises are able to offer SMA actuators and services. Within this network one company has to coordinate and organize the activities. Engineering service providers are particularly well-suited for this position. Especially small and medium-sized enterprises (SME) are involved in the production of SMAs. SMEs are companies whose balance sheet total is less than 19.25 million euros and whose turnover is less than 38.5 million euros. Furthermore, SMEs employ less than 250 employees. Another characteristic of SMEs is their limited diversification regarding their product portfolios as well as financing structure [24]. SMEs are facing several opportunities and challenges which are listed below. Especially their opportunities as regards SMAs have to be distinguished. Industrial SMA Niche markets are growing, consequently more SMEs are entering the markets compared to volume-oriented companies. Another opportunity is their potential as well as the tendency in terms of substitution and rationalization. Also the trend of miniaturization and modularization of components and group of components is of special interest. SMEs in the SMA market are also facing challenges. Based on industrial structural changes, their value chains have to be relocated. Another challenge an SME faces are its limited resources and competences (Figure 6).

\section{Conclusion}

Nowadays, shape memory actuators are mainly used in spaceand weight-reducing products. Thus, the potential of these innovative actuators are still not fully used. Especially in combination with appropriate software, the freedom of design of developers for future product solutions based on SMA actuators in the field of maintenance will increase. Today's business models in the field of SMA actuator systems are not holistic and oriented along the integrated value chain for SMA actuator systems. More complicated actuator systems and widespread in industrial applications foster integration of businesses. The low depth of value adding in the integrated value chain offers SMEs a chance to participate on this growing market, despite their limited resources. It is necessary to investigate whether the competences in core business of SMEs are capable of adding value and thus to compensate the lack of competence with SMA actuators. Additionally, SMEs can achieve a high depth of value adding by creating a virtual organization or network organization. In this case limiting the number of companies within the network is vital to safeguard interest and keep the communication effort low. To avoid a competitive situation within

\begin{tabular}{|c|c|}
\hline Opportunities & Challenges \\
\hline $\begin{array}{l}\text { - Trend of mirizaturization as well as } \\
\text { modularization of components and group of } \\
\text { - Gomponents } \\
\text { - Growth of industrial SMA niche markets in } \\
\text { - Development of SMA process technologies } \\
\text { and production processes } \\
\text { - Potential and tendency regarding substitution } \\
\text { - } \text { and rationalization } \\
\text { - } \text { High potential regarding flexibility } \\
\text { - Ge-use/ recycing }\end{array}$ & $\begin{array}{l}\text { - Relocalion of value ctrairis caused by the } \\
\text { industrial structural change } \\
\text { - Limited resources and (SMA) competences } \\
\text { - Development of specific SMA-norms to } \\
\text { minimizc risk }\end{array}$ \\
\hline
\end{tabular}

Figure 6: Challenges and opportunities from the perspective of small and medium-sized enterprises in the integrated value chain for shape memory actuator systems. the network, responsibilities and tasks have to be defined through contracts. Further studies should be performed to investigate shape memory applications regarding their value chain and their potentials for services. One focus should be the use of the integrated sensor effect of SMAs for maintenance in detail. This covers process designing: proper maintenance processes based on this effect, the evaluation of parameters such as accuracy for predicting actuator lifetime and the proof of this effect through an application. Moreover, value chains should be analyzed in combination with services as well as technology in general. Additionally, analyzing suitable types of organizations with respect to the size of a company can be valuable to provide companies guidance in the process of market entry and market development.

\section{Acknowledgement}

The authors acknowledge the funding of the hyProFGA project by the Eu through NRW.BANK through Ziel2. NRW-programm Automotive+Produktion.NRW

\section{References}

1. Meier H, Uhland E (2010) Integrated industrial goods and services: marketing development and providing product service systems. Springer-Vieweg Press, Berlin

2. Schonherr M (2013) Designing and implementing product-based services for the machining industry. Chemnitz, Germany.

3. Wohe G (2013) Introduction to business administration. Vahlen Press, Munich, Germany.

4. Poznanski S (2007) Customer integration for value creation: an empirical study on the example of structure financing. Deutscher University, Wiesbaden, Germany.

5. Laurischkat K (2012) Product-service systems: IT-supported designing and modelling of PSS service parts. Bochum, Germany.

6. Evanschitzky H (2003) Success of service networks: a network marketing approach. Deutscher Universitäts-Verlag, Wiesbaden, Germany.

7. Homburg C, Garbe B (1999) Towards an Improved Understanding of Industria Services: Quality Dimensions and Their Impact on Buyer-Seller Relationship.

8. Volker O (2012) Organization of industrial product service systems. Bochum, Germany.

9. Kortmann D (2007) Service design within industrial product service systems Bochum, Germany.

10. Nüttgens M, Heckmann M, Luzius M.J (1998) Service engineering a conceptual framework. Management und Consulting, Sonderausgabe Service Engineering.

11. Meffert H, Bruhn M (2003) service marketing: basics, concepts and methods. Gabler Press, Wiesbaden, Germany.

12. Corsten H (2007) Service management. Oldenbourg Press, Vienna.

13. Kleinaltenkamp M (2001) Definition and appearance of services. Handbook for service management. Gabler Press, Wiesbaden, Germany.

14. Czechowicz A, Langbein S (2012) The Development of Standardized Shape Memory Alloy Actuators. Conference Proceedings of Actuator 2012 Conference, Bremen, Germany.

15. Czechowicz A, Lygin K, Langbein S (2014) On the Potentials of Shape Memory Alloy Valves. Journal of Materials Engineering and Performance 23: 26872695.

16. Langbein S, Meier H, Czechowicz A (2011) Service systems for shape memory technology. Conference Proceedings of SMASIS2011, Arizona, USA.

17. Meier, H, Czechowicz A, Langbein S (2011) Controlled shape memory actuators with resistance feedback. Proceedings of Mechatronikkongress, VDI-Tagungsband 2011, pp. 345-350.

18. Rathmann C, Czechowicz A, Meier H (2013) An investigation of serviceoriented shape memory actuator systems for resource efficiency, Proceedings of the ASME 2013 Conference on Smart Materials, Adaptive Structures and Intelligent Systems, Snow Bird, USA.

19. Meier H, Czechowicz A, Haberland C (2009) Control loops with detection of 
Citation: Christian R, Stefanie K, Dieter K (2015) Opportunities and Challenges in the Value Chain for Companies through a Changing Understanding of Products on the Example of Shape Memory Actuators Systems. J Entrepren Organiz Manag 4: 130. doi:10.4172/2169-026X.1000130

inner electrical resistance and fatigue-behavior by activation of NiTi shape memory alloys. Proceedings of ESOMAT.

20. Pilch J, Heller L, Sittner P (2010) Heat Treatment of thin NiTi filaments by electric current. SMST e-Elastic newsletter, ASM International.

21. Malard B, Pilch J, Sittner P, Delville R, Curfs C (2011) In situ investigation of the fast microstructure evolution during electropulse treatment of cold drawn NiTi wires. Acta Materialia 59: 1542-1556.

22. Langbein S, Czechowicz A, Meier H (2011) Strategies for self-repairing shape memory alloy actuators. Journal of Materials Engineering and Performance 20: 564-569.
23. Rathmann C, Fleczok B, Lygin K, Meier H (2014) Optimizing the recycling process of a roof edge profile by using shape memory alloy connecting elements, Proceedings of the ASME 2014 Conference on Smart Materials, Adaptive Structures and Intelligent Systems. New Port, USA.

24. Ihlau S, Duscha H, Gödecke S (2013) Specialty for assessing SME - plausibility check for planning, taxes, capitalization. Wiesbaden: Springer Gabler Press.

25. IWU (2014) SMA-network. Retrieved 29/07/2014 from http://www.fgl-netzwerk. de/home. 